\title{
Infrared Thermography in the Evaluation of Dental Socket Healing After Photobiomodulation Therapy: A Case Report
}

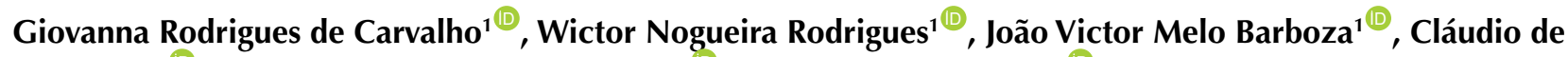

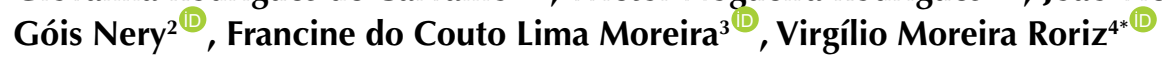 \\ ${ }^{1}$ Undergraduate Student, Faculty of Dentistry, Federal University of Goiás, Goiânia, Brazil \\ ${ }^{2}$ DDS, MSc, PhD, Associate Professor, Department of Orthodontics Faculty of Dentistry, Federal University of Goiás, \\ Goiânia, Brazil \\ ${ }^{3}$ DDS, MSc, PhD, Assistant Professor, Department of Special Care, Faculty of Dentistry, Federal University of Goiás, \\ Goiânia, Brazil \\ ${ }^{4} \mathrm{DDS}, \mathrm{MSc}, \mathrm{PhD}$, Assistant Professor, Department of Periodontology, Faculty of Dentistry, Federal University of Goiás, \\ Goiânia, Brazil
}

\section{*Correspondence to Virgílio Moreira Roriz; Adress: Faculty of Dentistry Avenida Universitária, $\mathrm{s} / \mathrm{n}$ - Setor Leste Universitário, Goiânia, Goiás, Brazil. \\ Tel: 55 (062) 3209-6068 Email:vmroriz@hotmail.com}

Published online March 2, 2021

\section{Introduction}

The extraction of the third molars is one of the most common procedures in oral surgery. ${ }^{1}$ The complexity of surgical extraction varies depending on the anatomical location of the surgical area and dental angulation. As the third molars are located in the posterior maxillomandibular region, a place associated with constant temporomandibular movements, their extraction usually results in a postoperative period associated with pain, edema and trismus. ${ }^{2}$ The face is prone to the formation of edema as it is intensely vascularized, in addition to involving bones and soft tissues. Researchers have suggested many methods to prevent these complaints, such as systemic and topical pre- and post-operative administration of anti-inflammatory drugs and laser therapy application, among others. ${ }^{3}$

The repair process is common to all surgical wounds and independent of the causal agent. Photobiomodulation therapy (PBMT) is an emerging technique that uses a lowpower laser (red or infrared) to modulate inflammation, accelerate wound healing and reduce pain and discomfort in different clinical situations. ${ }^{4,5}$

Studies have already demonstrated that a low-level laser is capable of promoting vasodilation and the production of growth factors, as well as angiogenesis, thus aiding wound repair. ${ }^{6,7}$ It has also been shown that PBMT is able to modulate blood flow after surgical trauma, inducing an increase in the microcirculation of lymphatic vessels. These vascular changes after the extraction of third molars can lead to a momentary temperature increase in the irradiated area. ${ }^{8}$

Some researchers have investigated the use of infrared thermography (IT) as a tool for evaluating the effectiveness of using a low-level laser after the extraction of third molars, showing local temperature coefficients in different postoperative periods. Clinical parameters such as pain, trismus and edema can also be correlated. ${ }^{3,9}$ Other authors have described the use of IT in the diagnosis and treatment of many diseases such as dental pulp pathologies, inflammatory arthritis and 
temporomandibular joint (TMJ) disorders. ${ }^{10}$

Therefore, the objective of this article was to evaluate, using thermography, the process of alveolar tissue healing after a tooth extraction in an area that received PBMT.

\section{Case Report}

A 36-year-old male patient was evaluated in the Dentistry School at the Federal University of Goiás, Brazil. After clinical and radiographic examinations of teeth 18 and 28 , it was observed that they were vestibularized and extruded, and had no antagonists, favoring mechanical trauma to the cheek mucosa. Therefore, after the consent of the patient, it was decided to extract them.

The extraction of teeth 18 and 28 was performed under local anesthesia $(20 \mathrm{mg} / \mathrm{mL}$ mepivacaine hydrochloride with $0.01 \mathrm{mg} / \mathrm{mL}$ epinephrine; 1 tube and $1 / 2$ tube per tooth respectively, DLA Pharmaceutical Ltda.), with intrasulcular incisions and detachment. Levers and forceps were used. Simple sutures were performed with 4-0 nylon thread. The procedure was uneventful and there was no need for an osteotomy. Subsequent drug prescription included Nimesulide $100 \mathrm{mg}$ (12/12 hours) for 3 days and Dipyrone sodium $500 \mathrm{mg}$ (6/6 hours) for 3 days, in case of pain.

Following the extraction, four sessions of PBMT were administered, using low-level laser equipment (Therapy $\left.\mathrm{EC}^{\circ}, \mathrm{DMC}, \mathrm{Brasil}\right)$, in a wavelength of $660 \mathrm{~nm}$, and a dose of $71 \mathrm{~J} / \mathrm{cm}^{2}(\mathrm{E}=2 \mathrm{~J} ; \mathrm{t}=2 \mathrm{~s} ; \mathrm{P}=0,1 \mathrm{~W})$ per tooth (Table 1). The PBMT sessions were carried out 7, 14, 28 and 42 days after surgery in the region around tooth 28 , which was chosen as it had the highest level of tissue damage seen clinically. The other side, the region around 18, was used

Table 1. Laser Parameters

\begin{tabular}{lc}
\hline Type of laser & Low-level laser \\
Emission mode & Continuous \\
Delivery system & Optical fiber \\
Energy distribution & By point \\
Peak power & $0.1 \mathrm{~W}$ \\
Average power & Not applicable \\
Spot diameter at focus & $0.3 \mathrm{~cm}$ \\
Focus spot area & $0.028 \mathrm{~cm}^{2}$ \\
Spot diameter at tissue & $0.3 \mathrm{~cm}^{2}$ \\
Focus-to-tissue & Against the tissue \\
Spot area at tissue & $0.028 \mathrm{~cm}^{2}$ \\
Peak power density at spot area & $3.57 \mathrm{~W} / \mathrm{cm}^{2}$ \\
Peak power density at tissue & $71 \mathrm{~J} / \mathrm{cm}^{2}$ (in this study; E=2 $\mathrm{J} /$ Tooth) \\
Average power density at spot area & Not applicable \\
Average power density at tissue & Not applicable \\
Beam divergence & Not applicable \\
Water irrigation & Not applicable \\
Air and aspirating airflow & Not applicable \\
\hline
\end{tabular}

as a control, without PBMT.

Images were taken using a thermographic camera (Thermal camera FLIR-C2 FLIR C2) to evaluate tissue repair before and after the extraction. The thermographic images were captured with a thermal sensitivity of $0.1^{\circ} \mathrm{C}$ (the patient was acclimatized for a period of 15 minutes before data collection, in a controlled temperature room, at around $23^{\circ} \mathrm{C}$ ) and analysed using specific software (Thermofy). The photos were taken from T0 to T5: T0 - before the extraction; T1 - immediately after the extraction; T2 - after the first PBMT session; T3 - after the second PBMT session; T4 - after the last PBMT session; T5 - 60 days after the teeth extraction.

The specific area on the face that suffers the repercussions of surgical trauma on the tissue was standardized: $r 3$ (the region corresponding to the upper third molars). Areas $\mathrm{r} 1$ and $\mathrm{r} 2$ represent the temporal and TMJ regions respectively (used for comparison).

Seven days postoperatively, the soft tissues of the alveolus were partially closed. The patient reported mild pain on the first day, which was resolved with an analgesic. There was no observed trismus nor facial edema and the sutures were removed. At this moment the first PBMT session $\left(660 \mathrm{~nm}, 71 \mathrm{~J} / \mathrm{cm}^{2}\right)$ was carried out, with one point of application in contact with the mucosa of the alveolus. Then the IT (T2) was performed, and the T2 image showed thermal variation between the control side and the treated side of -0.77 , representing an increase of $0.56^{\circ} \mathrm{C}$ in the temperature on the laser-treated side in relation to the day of the procedure. In Figure 1, image A represents the control side of the face and image $B$ represents the treated side.

The delta (A-B) in T3 showed a value of -0.44 on the side treated with a hyperradiant laser compared to the control side (Figure 2).

The 42-day post-extraction evaluation (last PBMT session) showed healing of the soft tissues. In the IT performed in that session, the delta (A-B) showed a variation of 0.62 on the treated side that was hyporradiant (lower temperature) compared to the control side (Figure 2). Due to the clinical conditions during this session, the acclimatization and image capture protocol was changed. The last PBMT session was subsequently applied.

The evaluation on day 60 post-extraction (T5) indicated that alveolus of the tooth 28 was completely closed (Figures 3 and 4 ). The delta at T5 showed a value of -0.80 on the hyperradiant treated side (Figure 2).

\section{Discussion}

Clinically the alveoli showed good healing. Regarding the alterations in the circulatory pattern observed after the surgical removal of the third molars, PBMT helped to reduce the inflammatory process that occurs after surgical trauma., ${ }^{3,11,12}$ After teeth extractions and irradiation by PBMT, a momentary increase in temperature can be experienced. Schindl et $\mathrm{al}^{13}$ demonstrated an increase 


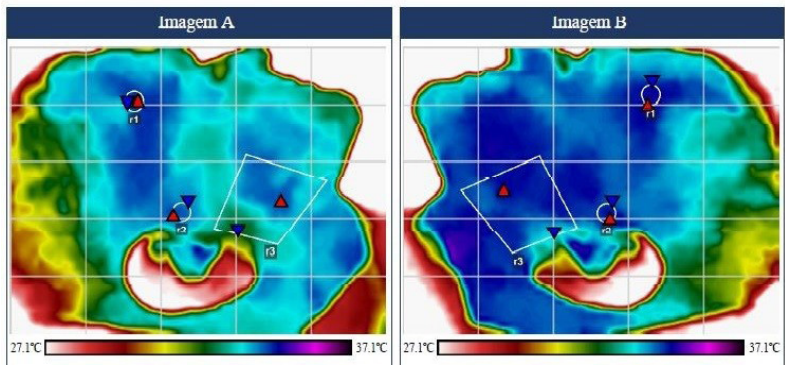

Figure 1. Time 2 - thermographic images. A - Control side B Treated Side ( $\mathrm{r} 3$ - upper third molars, $\mathrm{r} 1$ - temporal region, $\mathrm{r} 2$ - TMJ region)

Delta (A-B)

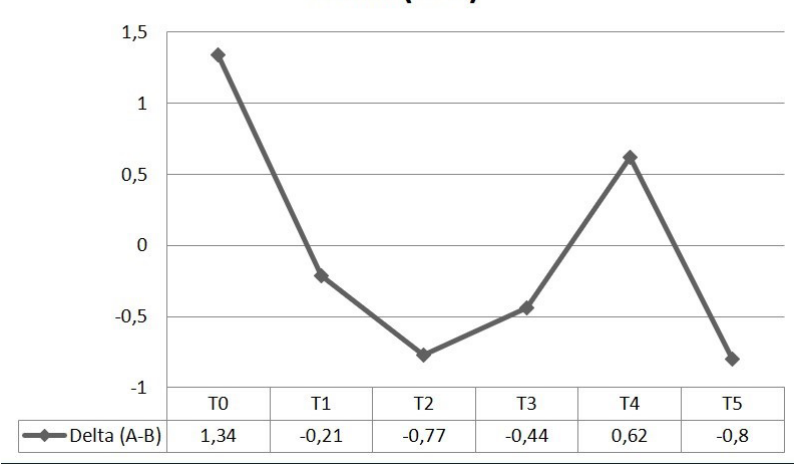

Figure 2. Thermographic takens showing numerical differences between the control side (A) and the treated side (B), represented by deltas

in temperature indicating the best blood supply after laser irradiation of varicose ulcers in diabetic patients. To evaluate the circulatory pattern of the lesion and the variation in the thermal coefficient, these authors used the IT technique, as in the current case report, although our patient was not diabetic.

Christensen et $\mathrm{al}^{14}$ showed that temperature can vary over short periods of time, including days, and also stated that thermography seems to be inadequate for measuring absolute temperatures or demonstrating an absolute difference in the long term. However, if a control region within the same individual (for example, the contralateral side) can be included, thermography appears to be promising for visualizing differences in relative temperature, as demonstrated in this case report.

According to DiBenedetto et al, ${ }^{15}$ a thermal differential $(\Delta \mathrm{T})$ above $0.3^{\circ} \mathrm{C}$ is indicative of abnormality, and in the present case, the treated side presented a delta higher than $0.3^{\circ} \mathrm{C}$ from the first laser application onwards. The treated side remained hyperradiating in the subsequent sessions except in T4, when the treated side was hyporradiant.

Batinjan et $\mathrm{al}^{16}$ evaluated the impact of PBMT on postoperative healing after the third molar extraction. The authors observed a significantly higher temperature $\left(1^{\circ} \mathrm{C}\right.$ higher) in patients who did not receive PBMT in the postoperative period, both on the third and seventh days after surgery, showing the anti-inflammatory effect and modulation of the circulatory pattern of PBMT. In the present case, the treated side showed a temperature increase of $0.76^{\circ} \mathrm{C}$ more than the untreated side, 7 days after surgery, and an increase of $0.44^{\circ} \mathrm{C}$ after 14 days. However, the thermographic record 42 days postoperatively showed a large decrease in temperature on the treated side, with an increase of $0.62^{\circ} \mathrm{C}$ more on the control side. It is thought that non-compliance with the protocols in this specific session, such as the ambient temperature, may have interfered with the thermal result found by IT.

The wavelength of the laser used in our case was 660 $\mathrm{nm}$ (red light), with a dose of $71 \mathrm{~J} / \mathrm{cm}^{2}$, and the treated side showed more rapid alveolar tissue healing compared to the control side. Dostalova et $\mathrm{al}^{9}$ used a low-level laser in a group after impacted third molar extraction, but they evaluated the effectiveness of PBMT based on immunological tests and IT. They used a wavelength of $830 \mathrm{~nm}$ and observed a $0.2^{\circ} \mathrm{C}$ temperature difference between the treated and non-treated sides. The authors concluded that the deepest alveolus wounds had no effect on the increase in face temperature.

In the present report, the thermal difference on the face before and immediately after the extraction procedure was numerically significant on the test side, being $1.3^{\circ} \mathrm{C}$ higher after the extraction. Kolosovas-Machuca et $\mathrm{al}^{17}$ also evaluated temperature changes during extractions

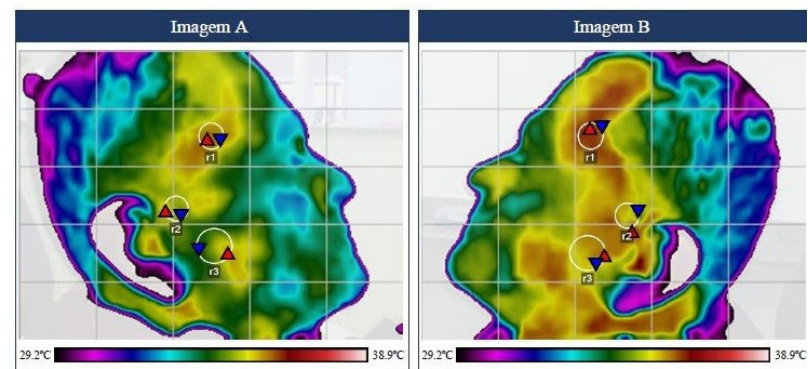

Figure 3. Time 5 - thermographic images. A - Control side B Treated Side. (r3 - upper third molars, $\mathrm{r} 1$ - temporal region, $\mathrm{r} 2$ - TMJ region)

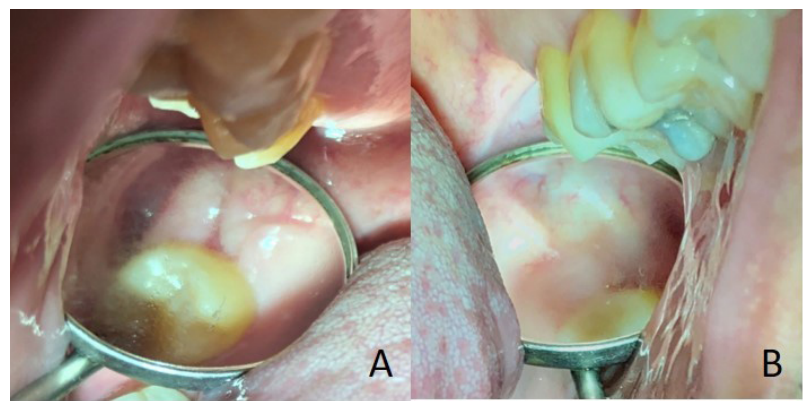

Figure 4. Clinical appearance in the region of teeth 18 (A) and 28 (B), respectively, 60 days after extraction. 
and found a significant difference between before the procedure and during the dental extraction, with an average difference of $4.07^{\circ} \mathrm{C}$. However, unlike the current report, they evaluated thermographic changes on the face at points located in the lacrimal caruncle region.

Pedreira et $\mathrm{al}^{3}$ evaluated the effect of a low-level infrared laser $(808 \mathrm{~nm})$ on postoperative clinical parameters (pain, trismus and swelling) after the extraction of the third molars. Circulatory patterns were also assessed by IT, which exhibited a temperature coefficient between different periods. A slight improvement in swelling, pain and trismus was observed in patients who received the laser. PBMT also had a clinically relevant influence on local circulation in the area close to the TMJ. In the present case, the patient did not present trismus or swelling. With the IT it was also possible to identify significant influences on local circulation, both in the region of the face corresponding to the third molar and in the TMJ and temporal regions.

Despite the limitations of the present report, it can be concluded that 60 days postoperatively, the side treated with PBMT was hyperradiating compared to the control side, possibly indicating the favorable effect of the laser on the healing process by accelerating tissue repair.

\section{Ethical Considerations}

Informed consent for the execution of the procedures was obtained from the patient.

\section{Conflict of Interests}

The authors declare no conflict of interest.

\section{References}

1. Falci SG, de Castro CR, Santos RC, de Souza Lima LD, Ramos-Jorge ML, Botelho AM, et al. Association between the presence of a partially erupted mandibular third molar and the existence of caries in the distal of the second molars. Int J Oral Maxillofac Surg. 2012; 41:1270-4. doi: 10.1016/j.ijom.2012.03.003.

2. de SantanaSantos T, de Souza-Santos AA, Martins-Filho PR, da Silva LC, de Oliveira e Silva ED, Gomes AC. Prediction of postoperative facial swelling, pain and trismus following third molar surgery based on preoperative variables. Med Oral Patol Oral Cir Bucal. 2013;18:e65-e70. doi: 104317/ medoral.18039.

3. Pedreira AA, Wanderley FG, Sa MF, Viena CS, Perez A, Hoshi R, et al. Thermographic and clinical evaluation of 808-nm laser photobiomodulation effects after third molar extraction. Minerva Stomatol. 2016;65 (4):213-22.

4. Parker S, Cronshaw M, Anagnostaki E, Bordin-Aykroyd SR, Lynch E. Systematic review of delivery parameters used in dental photobiomodulation therapy. Photobiomodul Photomed Laser Surg. 2019;37(12):784-797. doi: 10.1089/ photob.2019.4694.
5. Brignardello-Petersen R. Laser use may improve pain and wound healing in patients with recurrent aphtous stomatitis. J Am Dent Assoc. 2017;148:e112. doi: 10.1016/j. adaj.2017.05.025.

6. Hunter S, Langemo D, Hanson D, Anderson J, Thompson P. The use of monochromatic infrared energy in wound management. Adv Skin Wound Care. 2007;20:265-6. doi: 10.1097/01.asw.0000269312.45886.00.

7. Opel DR, Hagstrom E, Pace AK, Sisto K, Hirano-Ali SA, Desai $S$, et al. Light-emitting diodes: a brief review and clinical experience. J Clin Aesthet Dermatol. 2015;8:36-44.

8. Bagavathiappan S, Saravanan T, Philip J, Jayakumar T, Raj B, Karunanithi R, et al. Infrared thermal imaging for detection of peripheral vascular disorders. J Med Phys. 2009;34(1):43-47. doi: 10.4103/0971-6203.48720.

9. Dostalova T, Kroulikova V, Podzimek S, Jelinková H. Lowlevel laser therapy after wisdom teeth surgery: evaluation of immunologic markers (secretory immunoglobulin A and lysozyme levels) and thermographic examination: placebo controlled study. Photomed Laser Surg. 2017;35(11):616-21. doi: 10.1089/pho.2016.4214.

10. de Melo DP, Bento PM, Peixoto LR, Martins SKLD, Martins CC. Is infrared thermography effective in the diagnosis of temporomandibular disorders? A systematic review. Oral Surg Oral Med Oral Pathol Oral Radiol. 2019;127(2):185-192. doi: 10.1016/j.0ooo.2018.09.006.

11. de Araújo JGL, Araújo EMDS, Rodrigues FCN, Paschoal MAB, Lago ADN. High power laser and photobiomodulation in oral surgery: case report. J Lasers Med Sci. 2019;10(1):75-78. doi: 10.15171/jlms.2019.12.

12. Kulkarni S, Meer M, George R. Efficacy of photobiomodulation on accelerating bone healing after tooth extraction: a systematic review. Lasers Med Sci. 2019; 34(4): 685-692. doi: 10.1007/s10103-018-2641-3.

13. Schindl A, Schindl M, Schön H, Knobler R, Havelec L, Schindl L. Low-intensity laser irradiation improves skin circulation in patients with diabetic microangiopathy. Diabetes Care. 1998;21(4):580-4. doi: 10.2337/ diacare.21.4.580.

14. Christensen J, Matzen LH, Vaeth M, Schou S, Wenzel A. Thermography as a quantitative imaging method for assessing postoperative inflammation. Dentomaxillofac Radiol. 2012;41(6): 494-9. doi: 10.1259/dmfr/98447974.

15. DiBenedetto $M$, Yoshida $M$, Sharp $M$, Jones $B$. Foot evaluation by infrared imaging. Mil Med. 2002;167(5):384-92.

16. Batinjan G, Zore Z, Čelebić A, Papić M, Gabrić Pandurić D, Filipović Zore I. Thermographic monitoring of wound healing and oral health-related quality of life in patients treated with laser (aPDT) after impacted mandibular third molar removal. Int $J$ Oral Maxillofac Surg. 2014;43(12):1503-8. doi: 10.1016/j.ijom.2014.09.003.

17. Kolosovas-Machuca ES, Martínez-Jiménez MA, RamírezGarcíaLuna JL, et al. Pain Measurement through temperature changes in children undergoing dental extractions. Pain Res Manag. 2016;2016:4372617. doi: 10.1155/2016/4372617. 